\title{
Measuring and Modeling of $P$ - and S-Wave Velocities on Crustal Rocks: A Key for the Interpretation of Seismic Reflection and Refraction Data
}

\author{
Hartmut Kern \\ Institut für Geowissenschaften, Universität Kiel, 24098 Kiel, Germany \\ Correspondence should be addressed to Hartmut Kern, kern@min.uni-kiel.de \\ Received 7 January 2011; Accepted 20 February 2011 \\ Academic Editor: Yu Zhang \\ Copyright (C) 2011 Hartmut Kern. This is an open access article distributed under the Creative Commons Attribution License, \\ which permits unrestricted use, distribution, and reproduction in any medium, provided the original work is properly cited.

\begin{abstract}
Lithologic interpretations of the earth crust from seismic wave velocities are non-unique so that inferences about composition can not be drawn. In order to evaluate how elastic properties of rock materials are controlled by lithology at in situ pressures and temperatures, compressional $(\mathrm{Vp})$, shear wave velocities $(\mathrm{Vs})$ and velocity anisotropy of crustal rocks were measured at conditions of greater depth. The first part deals with the interdependence of elastic wave propagation and the physical and lithological parameters. In the second part data from laboratory seismic measurements and theoretical calculations are used to interpret (1) a shallow seismic reflection line (SE Finland) and (2) a refraction profile of a deep crust (Central China). The comparison of the calculated velocities with the experimentally-derived in situ velocities of the Finnish crustal rocks give hints that microcracks have an important bearing on the in situ seismic velocities, velocity anisotropy and the reflectivity observed at relative shallow depth. The coupling of the experimentally-derived in situ velocities of P- and S-wave and corresponding Poisson's ratios of relevant exhumed high-grade metamorphic crustal rocks from Central China with respective data from seismic refraction profiling provided a key for the lithologic interpretation of a deep seismic crustal structure.
\end{abstract}

\section{Introduction}

Investigation of the structure and composition of the earth's crust and upper mantle is a big challenge in Earth Sciences. Direct information about the structure and composition of the deep crust can be obtained either from crustal terrains exposed at the surface (e.g., $[1,2]$ ) or from xenoliths brought to the surface by magmas (e.g., [3]). Deeply eroded Precambrian terrains (e.g., Srilanka), and upthrust tectonic slices in orogenic belts (e.g., Ivrea Zone, N. Italy; Serre Mountains, S. Calabria; Kapuskasing Zone, Canada) provide perhaps the best geologic guides to structural style and composition at depth. Such rocks are important in providing direct data although they contain a mixed message as they are no longer the in situ deep crust.

Indirect information about the structure and composition of the inaccessible deep crust (and upper mantle) is obtained by geophysical surveys. Most important is seismic reflection and refraction profiling, and both techniques have been successfully used (independently or in combination with data from electrical, gravity, and magnetic investigations) to probe the deep crust and upper mantle. Seismic reflection patterns provide a structural image of the crust, and seismic refraction profiles give us information about the velocity distribution within the crust. The measured seismic velocity structures are very helpful in providing a rough characterization of the earth's crust in different tectonic environments, but they are nonunique so that inferences about composition cannot be drawn from wave velocities (at least P-wave velocities). Even in case that we can directly correlate various lithologies with, for example, sonic log or VSP data (Kola superdeep borehole, Russia; KTB, Germany), a basic question to be answered remains: why are the in situ properties as they are, and which factors control the in situ rock properties? The basic reason for this ambiguity is that crustal and mantle rocks are very complex materials and that their seismic properties at depth are affected in a very complex manner by a number of lithologic and physical factors. P- and S-wave velocities are controlled by the matrix (intrinsic) properties of the rocks 


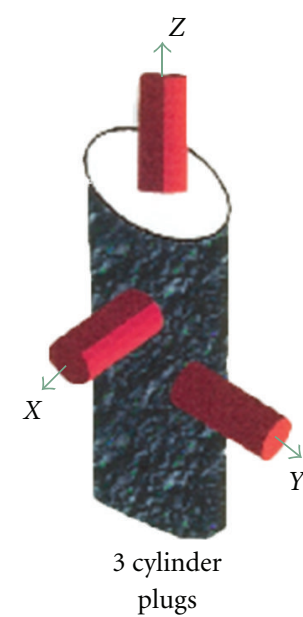

(a)

a)

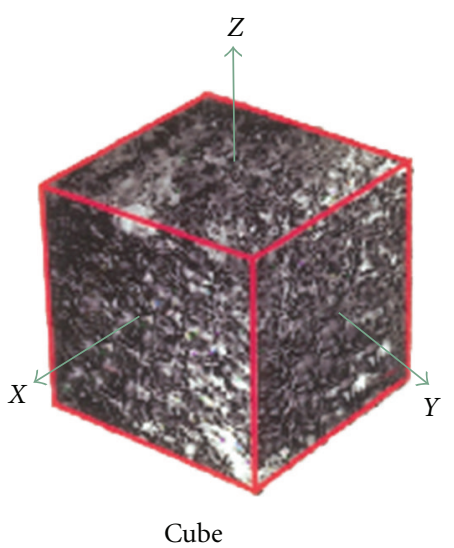

Cube

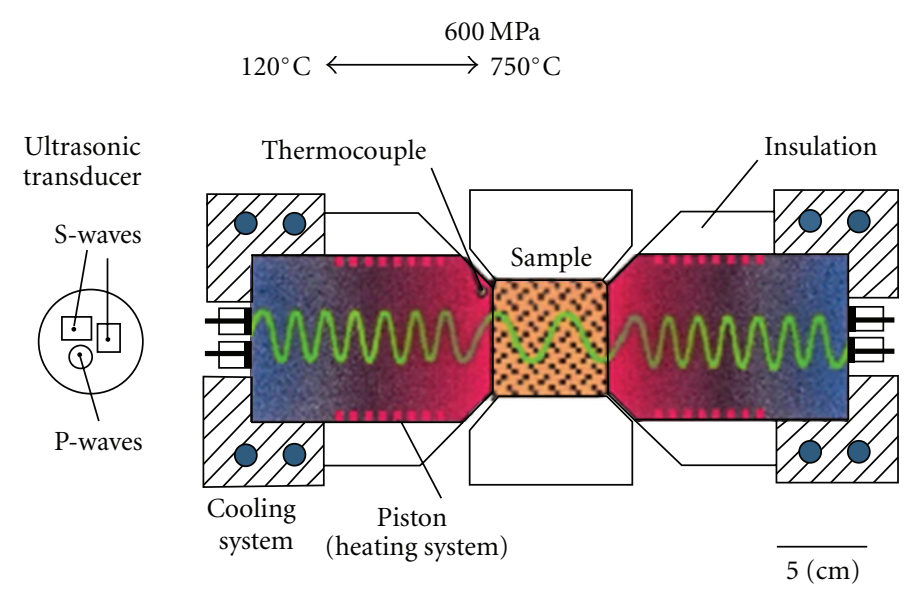

(b)

FIGURE 1: Commonly used sample geometries for laboratory seismic measurements (a) and the piston-sample-transducer arrangement in a multianvil pressure apparatus (b).

(mineral mode, chemical composition, metamorphic grade, and crystallographic preferred orientation of constituent minerals) and by the physical environment of the crust (temperature, pressure, porosity, fluid content, etc.).

A unique ability to correlate the seismic data with the structure and composition of the in situ deep crust can be provided by coupling experimentally determined or calculated P- and S-wave velocities for relevant crustal rocks collected from surface outcrops or from xenoliths, simulating in situ conditions: (1) by laboratory seismic measurements at actual PT conditions (e.g., $[4,5])$ and (2) by calculations from modal analyses and elastic properties of the rockforming minerals and their pressure and temperature derivatives (e.g., [6]).

In the first part of this paper, we will show, as an example, how the seismic properties of a crustal rock are affected by pressure and temperature and analyze the relationship between velocities and structural and textural characteristics of the rock. We will focus on the directional dependence (anisotropy) of P- and S-wave velocities at PT conditions. In the second part, we will interpret seismic field data on the basis of measured and calculated velocities derived from relevant crustal rocks for two case studies: Firstly, we will investigate the nature of seismic reflections within the $2500 \mathrm{~m}$ crustal section penetrated by the Outokumpu scientific drill hole (SE Finland), and secondly, we will give a lithologic interpretation for a seismic refraction profile crossing the ultrahigh pressure (UHP) metamorphic belt of the Dabie mountains (China). (for details, see [7] and [5], resp.).

\section{Laboratory Measurements of P- and S-Wave Velocities}

Two sample geometries are commonly used for the experimental determination of elastic wave velocities and their directional dependence (anisotropy): (1) jacketed cylindrical samples in an internally heated fluid or gas apparatus
(Figure 1(a), left) and (2) unjacketed cube-shaped specimens in an externally heated multianvil apparatus (Figure 1(a), right). On cylindrical samples, $\mathrm{Vp}$ and Vs measurements can be done only in one direction so that experiments on three sample cylinders taken in the three structural-related orthogonal directions are needed for the determination of velocity anisotropy. On cube-shaped samples, measurements of $\mathrm{Vp}$ and $\mathrm{Vs}$ can be done simultaneously in three orthogonal directions. In general, measurements are carried out in the $X, Y$, and $Z$ directions of the foliation-related structural frame ( $X Y$ is foliation, $X$ is lineation and $Z$ is foliation normal).

In our lab, measurements of $\mathrm{P}$ - and S-wave velocities are made on sample cubes ( $43 \mathrm{~mm}$ on edges) in a multianvil apparatus using the pulse transmission technique with transducers operating at 2 and $1 \mathrm{MHz}$ for P- and S-waves, respectively. As illustrated in Figure 1(b), the piston-sampletransducer arrangement allows simultaneous measurements of $\mathrm{Vp}$ and $\mathrm{Vs}$ and their directional dependence (velocity anisotropy) in the $X, Y$, and $Z$ directions of the sample cube as a function of pressure (up to $600 \mathrm{MPa}$ ) and temperature (up to $700^{\circ} \mathrm{C}$ ) and direct determination of length changes (volume change) from the piston displacement. Shear wave splitting (Vs1-Vs2) is measured by two sets of orthogonally polarized transducers with perpendicular polarization directions. A complete set of measured data comprises three Pwave velocities and six S-wave velocities along with the length changes (volume change) of the sample. A full description of the apparatus is given in [8].

To illustrate the effect of pressure and temperature on elastic wave velocities, Figure 2 presents experimental data for a biotite gneiss (OKU 578) from the Outokumpu scientific deep drill hole (see Section 3). The biotite gneiss sample is recovered from $578 \mathrm{~m}$ depth and made up by 34.1 vol- $\%$ quartz, 19.9 vol.- $\%$ plagioclase, 28.4 vol.- $\%$ biotite and 16.7 vol.- $\%$ muscovite. The modal compositions of all rock samples were calculated from bulk rock (X-ray fluorescence 


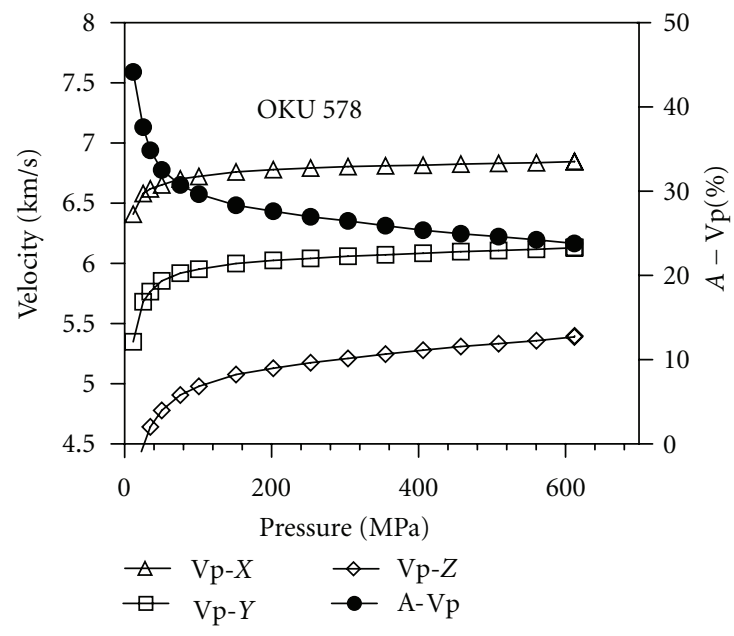

(a)

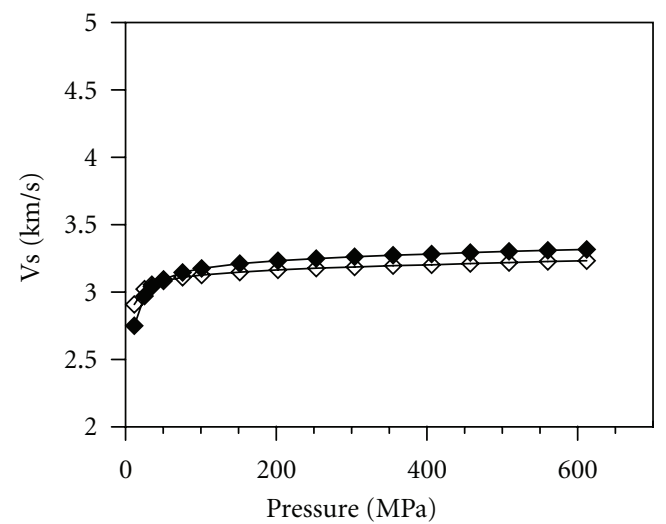

$$
\diamond \mathrm{Vs}-Z X
$$$$
\multimap \text { Vs- } Z Y
$$

(c)

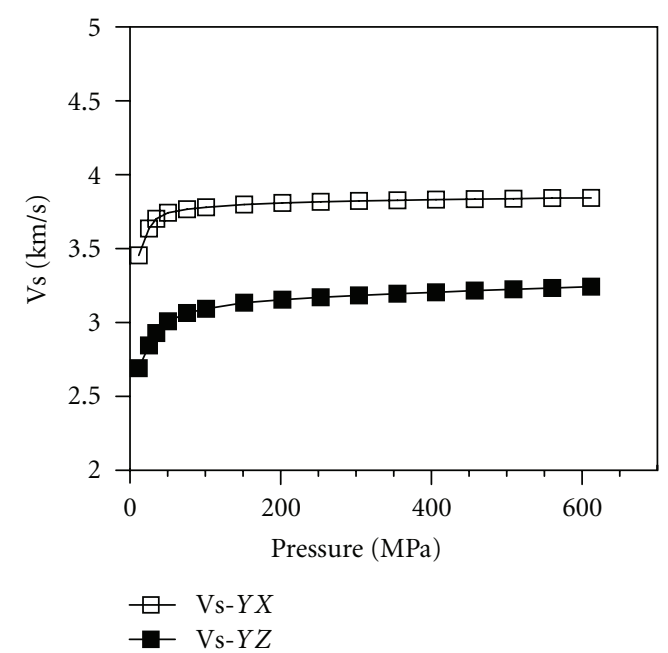

$(\mathrm{e})$

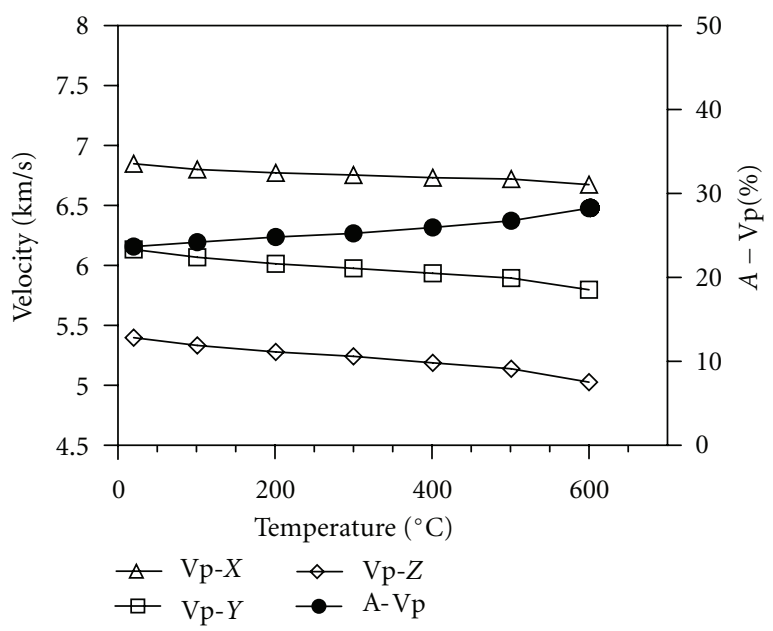

(b)

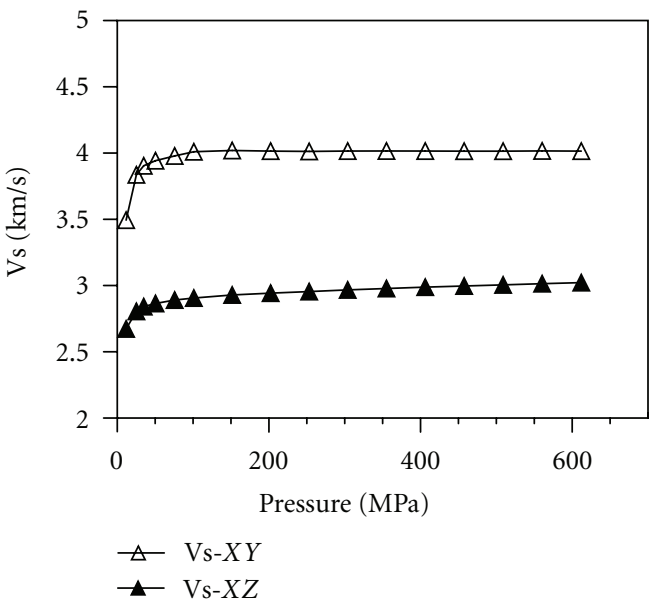

(d)

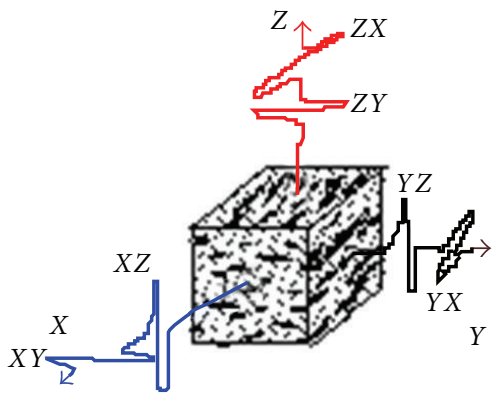

(f)

FIGURE 2: P- and S-wave velocities as a function of pressure up to $600 \mathrm{MPa}$ (room temperature) (Figure (a), (c)-(e), resp.) of a biotite gneiss (OKU 578) from Outokumpu, along with the temperature dependence of P-wave velocities measured at $600 \mathrm{MPa}$ confining pressure (b). (f) illustrates the measuring directions of $\mathrm{P}$ - and $\mathrm{S}$-wave velocities and shear wave polarization according the foliation-related structural frame $X, Y$, and $Z$ ( $X Y$ is foliation, $X$ is lineation, and $Z$ is foliation normal). 
analysis, XRF) and mineral chemistry (microprobe), using least square fitting $[7,9]$.

Compressional and shear wave velocities measured in $X, Y$, and $Z$ as a function of pressure (up to $600 \mathrm{MPa}$ ) at room temperature, along with the corresponding velocity anisotropy of P-waves (A-Vp) are plotted in Figure 2(a) and Figures 2(c)-2(e). P- and S-wave velocities are denoted by $\mathrm{Vp}_{i}$ and $\mathrm{Vs}_{i j}$, respectively. The first subscript $i$ of $\mathrm{Vp}$ and $\mathrm{Vs}$ indicates the propagation direction, and the second subscript $j$ of $\mathrm{Vs}_{i}$ indicates the polarization direction of the shear wave (Figure 2(f)). Anisotropy is defined by the percent differences between maximum and minimum velocity with respect to mean velocity [10].

At increasing confining pressure, $\mathrm{P}$ - and $\mathrm{S}$-wave velocities show a nonlinear increase approaching linear behaviour above about $200 \mathrm{MPa}$. The nonlinear rise on the curves is due to progressive closure of microcracks, typically illustrating the pressure sensitivity of $\mathrm{P}$ - and S-wave velocities. The velocities defining the nonlinear parts of the velocity versus. pressure curves (Figure 2(a)) can be used to interpret seismic data at shallow crustal depth (see Section 3). The linear lopes of the curves reflect the intrinsic rock properties. They are basically controlled by the volume percentage of major minerals, their single crystal elastic properties and their crystallographic preferred orientation (CPO). Increase of temperature at the high confining pressure of $600 \mathrm{MPa}$ that prevents thermal cracking results in slight linear decrease in wave velocities (Figure 2(b)). From the regression of the linear parts of the pressure (200-600 MPa) and temperature curves $\left(20^{\circ} \mathrm{C}-600^{\circ} \mathrm{C}\right)$ one can derive the intrinsic pressure and temperature derivatives of velocities and the reference velocity $\mathrm{V}_{0}$, which is the projected velocity of a nonporous or crack-free compacted rock at zero pressure. These data allow one to extrapolate seismic velocities to greater depth (where cracks are closed) for any $\mathrm{P} / \mathrm{T}$ condition within the stability field of the constituent assemblage of rock-forming minerals (see Section 4).

The significant differences of $\mathrm{P}$-wave velocities measured in the three structural directions $X, Y$, and $Z$ of the Outokumpu biotite gneiss (OKU 578) indicate strong velocity anisotropy (Figure 2(a)). Anisotropy is typical for most of the rocks constituting the earth's crust (e.g., [11-13]). Highest velocities are generally measured parallel to foliation (XY-plane) and lineation $[\mathrm{X}]$ and lowest normal to foliation. Anisotropy (A-Vp) is almost highest at low pressure (Figure 2(a)) due to the effects resulting from oriented microcracks and crystallographic preferred orientation of the rock-forming minerals. Increasing pressure reduces the effect of cracks and the residual (intrinsic) anisotropy is mainly due to CPO (e.g., $[14,15])$. Splitting of the two orthogonally polarized shear waves (S1 and S2) is an important diagnostic phenomenon for seismic anisotropy [16]. It is closely related to the structural frame (Figures 2(c)-2(e). Pronounced shear wave splitting is generally observed parallel to $X$ and $Y$ within the foliation plane with the fast split shear wave being polarized parallel to foliation. Normal to foliation, shear wave splitting is generally low. Note that in the Outokumpu biotite gneiss (OKU 578), there is practically no shear wave splitting observed normal to foliation (Figure 2(c)). This direction marks a singularity [16]; that is, S-waves propagate in this direction like in an isotropic medium.

Anisotropy of P- and S-wave velocities as well as shear wave splitting of the biotite gneiss (OKU 578) is mainly due to the high volume proportions of biotite and muscovite (about 28 vol.-\% and 17 vol.-\% resp.), their strong CPO and the very high anisotropy of both minerals $(>40 \%)$. It should be noted that shape preferred orientation (SPO) of biotite and muscovite as well as oriented microcracks may also contribute to bulk anisotropy [17-19].

The experimentally derived relations between $\mathrm{P}$ - and $\mathrm{S}$-wave wave propagation and shear wave polarization to the structural frame (foliation, lineation) are confirmed by $3 \mathrm{D}$ velocity calculations based on the preferred orientation (CPO) of the constituent minerals, their volume fraction, the crystal densities and their elastic stiffness coefficients [7, 17].

\section{The Nature of Seismic Reflections Observed within a Crustal Section at Shallow Depth}

Here, we use calculated and experimental velocity data of crustal rocks sampled by the Outokumpu deep drill hole (SE, Finland) for an interpretation of sonic log data and of crustal reflections observed on a high resolution reflection profile (OKU-1) close to the bore hole (Figures 3(a) and 3(b)).

The high-resolution seismic line (OKU-1) in SE, Finland, (Figure 3(c)) has revealed a high reflectivity zone between about $1300 \mathrm{~m}-1500 \mathrm{~m}$ depth [20]. The line is close to the Outokumpu scientific drill hole which has sampled a $2500 \mathrm{~m}$ crustal section within Paleoproterozoic metasedimentary and ophiolitic sequences [21]. The drilled Precambrian crustal section comprises a $1300 \mathrm{~m}$ thick biotite gneiss series at top, followed by a $200 \mathrm{~m}$ thick metaophiolite sequence, underlain again by a $500 \mathrm{~m}$ thick biotite gneiss sequence with intercalations of amphibolite and pegmatitic granite. From $2000 \mathrm{~m}$ downward the dominant rock types are pegmatitic granites (see Figure 4, left).

We selected 29 core samples covering the depth range $198 \mathrm{~m}-2491 \mathrm{~m}$ for petrophysical studies [7, 17], in order to interpret sonic log data and to provide constraints on the nature of the reflectivity zone revealed by the high resolution reflection line. For all samples, we calculated the average (isotropic) intrinsic P- and S-wave velocities by combining the modal composition of the rocks with the respective velocities of the isotropic monomineralic aggregates (VRH averages) of the constituent minerals [22]. On 13 oven-dried $\left(80^{\circ} \mathrm{C}\right)$ cube-shaped samples representing main lithologies, we measured $\mathrm{P}$ - and S-wave velocities in 3 orthogonal directions at pressures up to $600 \mathrm{MPa}$ in order to determine their cracks sensitivity and directional dependence. Velocity measurements as well as 3D velocity calculations, based on neutron diffraction CPO measurements $[7,17]$, show that velocity anisotropy and shear wave splitting are important properties of the biotite gneisses that dominate about $70 \%$ of the drilled crustal section. In Figure 4 (left), we compare the calculated velocities and the experimentally derived in situ velocities with sonic log data. It is clear from the diagram that the calculated intrinsic velocities (red symbols) are generally higher than those determined by the sonic 


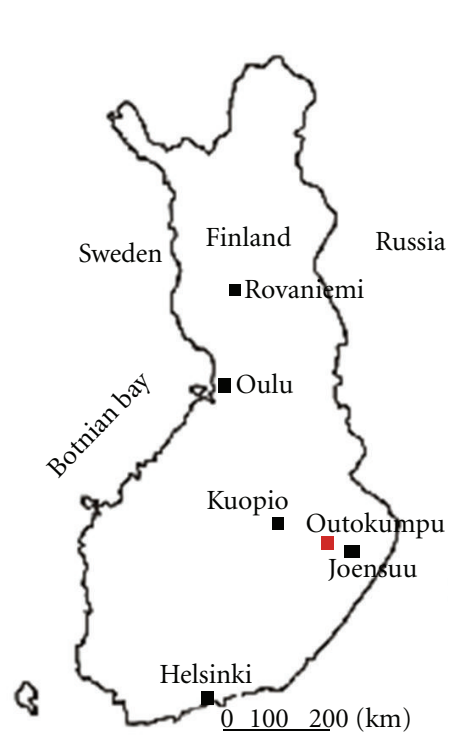

(a)

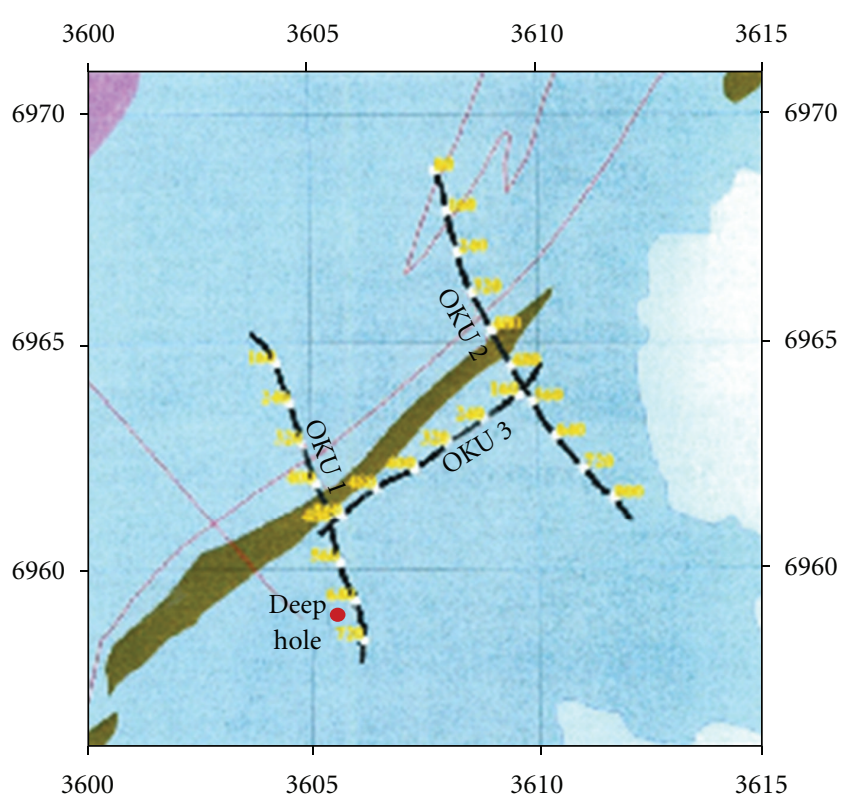

(b)

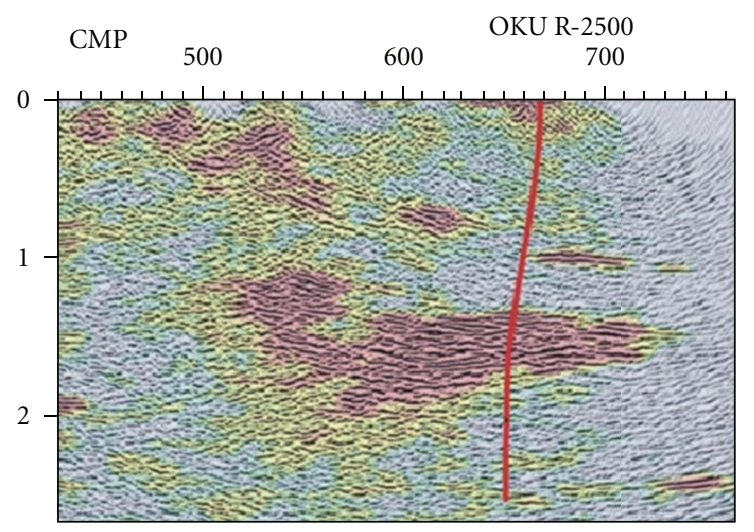

(c)

FIgURE 3: Location of the Outokumpu scientific drill hole (a), along with high-resolution reflection lines (b) and the end of the migrated OKU-1 section at Outokumpu (c) (after Heikkinen et al. [20] and Kukkonen et al. [21] resp.).

log, whereas the experimentally derived in situ data (green symbols) fit markedly better. Therefore, we conclude that microcracks that are not completely closed at the relatively shallow depth have an important bearing on the in situ velocities in addition to the lithologic control. Importantly, the experimentally derived velocities propagating in the $Z$ direction (black symbols), that is, normal to subnormal to foliation (parallel to the bore hole), are closest to the sonic $\log$ data. It should be noted, however, that the possible effect of pore fluids has not been taken into account.

For assessing the potential importance of the various lithologic interfaces as seismic reflectors and the role of anisotropy, we calculated from the acoustic impedances $I$ (velocity multiplied with density) the corresponding normal incidence reflection coefficients $\left[R_{c}=\left(I_{1}-I_{2}\right) /\left(I_{1}+\right.\right.$ $\left.I_{2}\right)$ ]. Figure 4 (right) compares the reflection coefficients derived from modal mineralogy and the isotropic aggregate velocities of the constituent minerals (left vertical line) with those derived from the average velocities obtained by the laboratory seismic measurements for the in situ pressure conditions (middle vertical line). Also included is a calculation based on velocities measured normal to foliation (parallel to $Z$ ), taking into account that the foliation of the rocks constituting the $2500 \mathrm{~m}$ crustal section is normal to subnormal to the borhole (right vertical line). The data refer to an average density of $2.57 \mathrm{~g} / \mathrm{cm}^{3}$. According to Warner [23], reflection coefficients close to $+/-0.1$ are required for strong seismic reflections. From the reflection coefficients $R_{c}$ derived from modeled as well as from experimental in situ velocities, we conclude that the multiple reflections within the metaophiolite series (Figure 4, right) are caused by the variation in lithology. This holds, in particular, for the contacts of the diopside skarn to serpentinites and serpentinites to pyr-hbl-gneiss and phlogopite-graph-gneiss. 


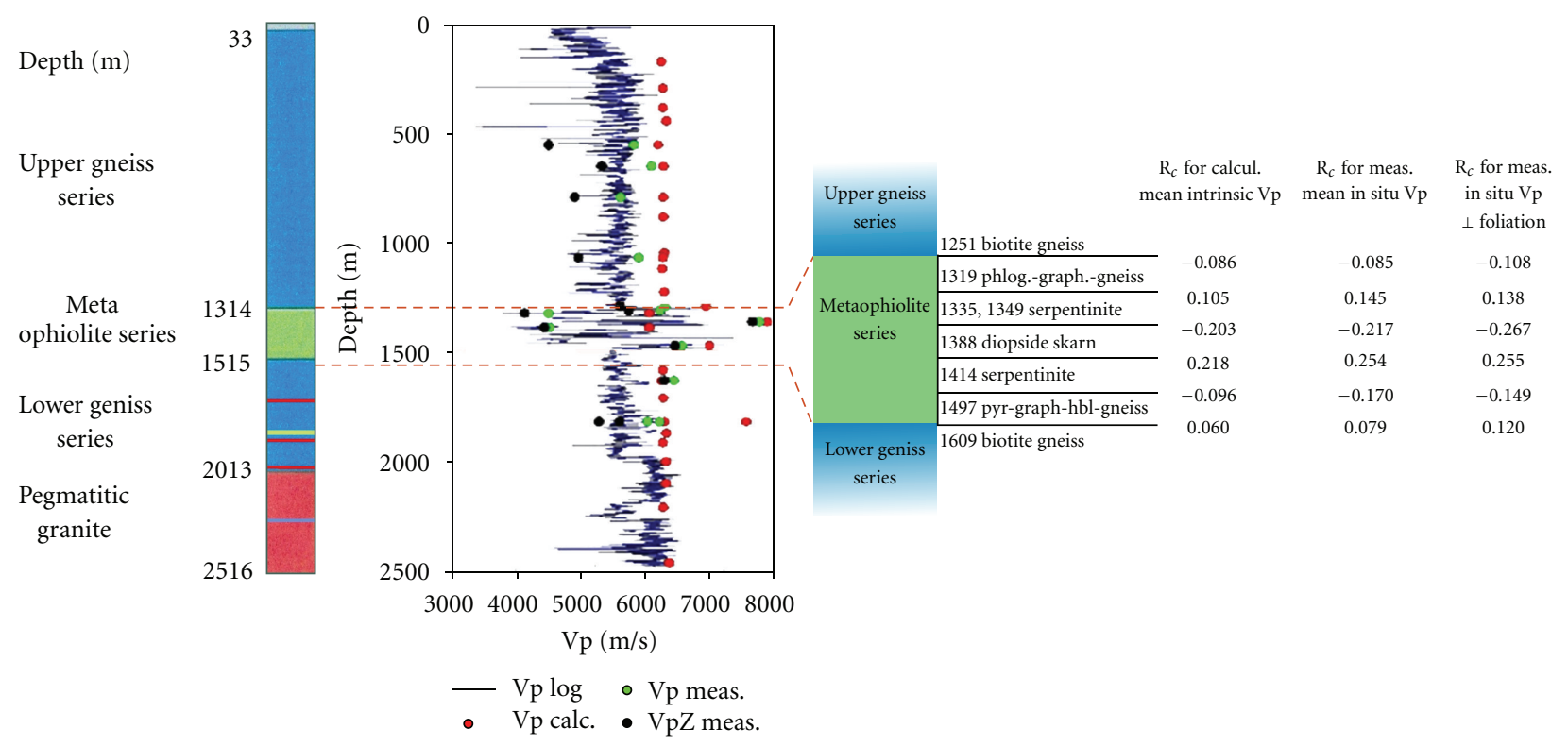

FIGURE 4: Comparison of sonic log data of the Outokumpu scientific drill hole with calculated intrinsic and measured in situ velocities of the investigated samples (left) along with calculated reflection coefficients $\left(R_{c}\right)$ for the different lithologies (right).

From the strong directional dependence of wave propagation (slowest velocities normal to foliation; parallel to $Z$ ), we infer that reflectivity at the contacts of the upper and lower gneiss series with the metaophiolite series is significantly enhanced by effects from oriented microcracks that are not completely closed, in addition to the strong crystallographic preferred orientation (CPO) of the constituent phyllosilicates (biotite and muscovite) in the upper and lower gneiss series. From the experimental results, we infer that variations in lithology within the ophiolite-related assemblage are also responsible for the strong seismic reflections revealed by the highresolution seismic reflection line (OKU-1) close to the borehole at the depth of $1300 \mathrm{~m}-1500 \mathrm{~m}$ (Figure 3(c)).

\section{Lithologic Interpretation of a Crustal Seismic Velocity Structure Based on In Situ P- and S-Wave Velocities Derived from Experimental Data}

We selected a seismic refraction profile crossing the Dabie Mountain (Central China) in order to document the potential of laboratory seismic measurements simulating in situ conditions for the lithologic interpretation of a seismic crustal velocity structure.

The Dabie-Sulu ultrahigh-pressure metamorphic belt (Figure 5(a)) represents a zone in which upper and lower continental crust has been subducted and then rapidly exhumed from the mantle back into the crust [24]. Seismic refraction profiles [25] reveal a four layer structure (upper, middle, upper-lower, and lowermost crust) with an average thickness of $34 \mathrm{~km}$ (Figure 5(b)). Experimental petrophysical investigations on about 30 UHP rock samples collected form surfaces exposures [5] provide the basis for a lithologic interpretation of the seismic velocity structure. The rock samples span compositions from felsic through intermediate to mafic, and metamorphic grades up to granulite and eclogite facies. They comprise tonalitic and trondhjemitic gneisses, metapelites, metagabbros, amphibolites, intermediate and mafic granulites, and eclogites. The experimental data include compressional $(\mathrm{Vp})$ and shear wave velocities (Vs), velocity anisotropy, density, and intrinsic pressure and temperature derivatives of $\mathrm{Vp}$ and $\mathrm{Vs}$ derived from regression of the linear segments of the pressure (300$600 \mathrm{MPa})$ and temperature curves $\left(20^{\circ} \mathrm{C}-500^{\circ} \mathrm{C}\right)$. Using a regional geotherm, velocity depth profiles were calculated for the different lithologies [5]. Because most of the cracks and fractures are closed at greater depth and the effects of cracks are thus largely eliminated, we used the intrinsic P-wave velocities together with the Poisson's ratios for a lithologic interpretation of the seismic model (Figure 5(b)) evaluated from seismic refraction data. The interpretation is based on the averages of velocities measured in the three directions $X, Y$, and $Z$, because no indications of seismic anisotropy are reflected by the seismic data. The combined measurements of P- and S-wave velocities on UHP rocks and the availability of seismic data on the P-wave velocity and the Poisson's ratio structure along a profile crossing the Dabie Mountains [25] provides valuable constraints on the composition of the crust. Figure 6 compares the ranges of experimentally derived in situ velocities and Poisson's ratios with the respective seismic refraction data (red circles). From the comparison, we infer that the seismic properties of the middle crust are in accordance with those measured on amphibolite-facies tonalitic-trondhjemitic and granitic gneisses. The upper-lower and lowermost crust may be interpreted by intermediate (or mixtures of felsic and mafic granulite) and mafic granulites, respectively. From the 

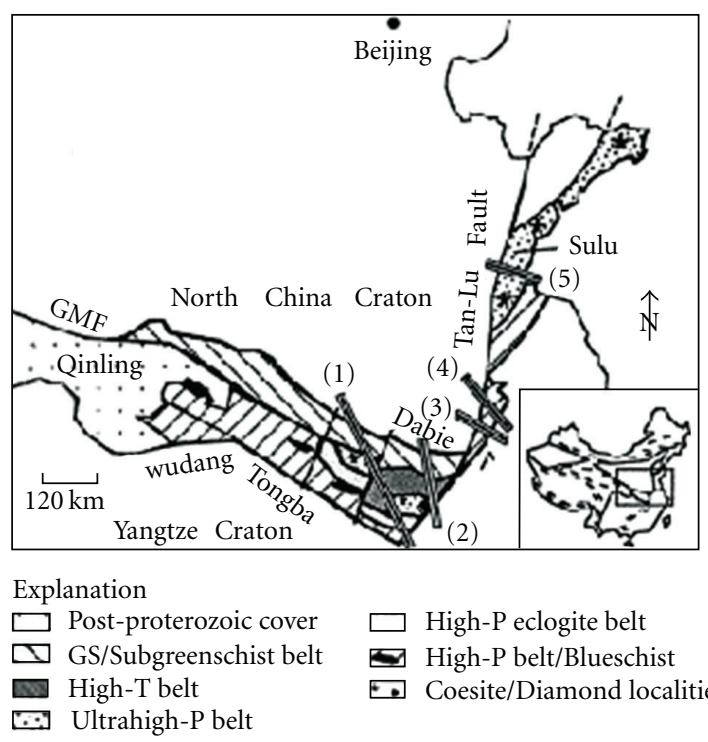

(a)

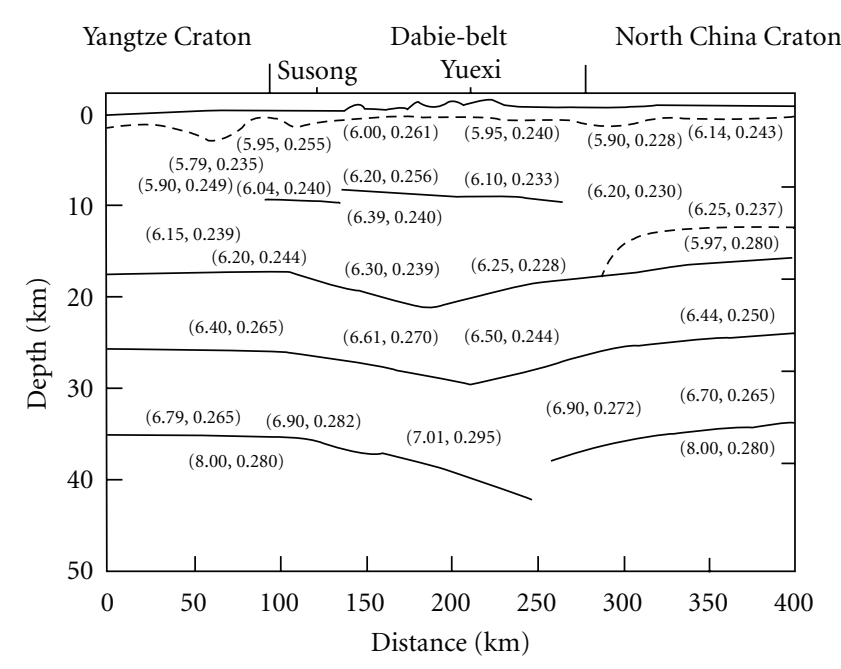

(b)

Figure 5: Regional map (a) of the Dabie-Sulu area [24] and a seismic model structure for P-wave velocities and Poisson's ratios (b) for the $34 \mathrm{~km}$ thick crust [25].
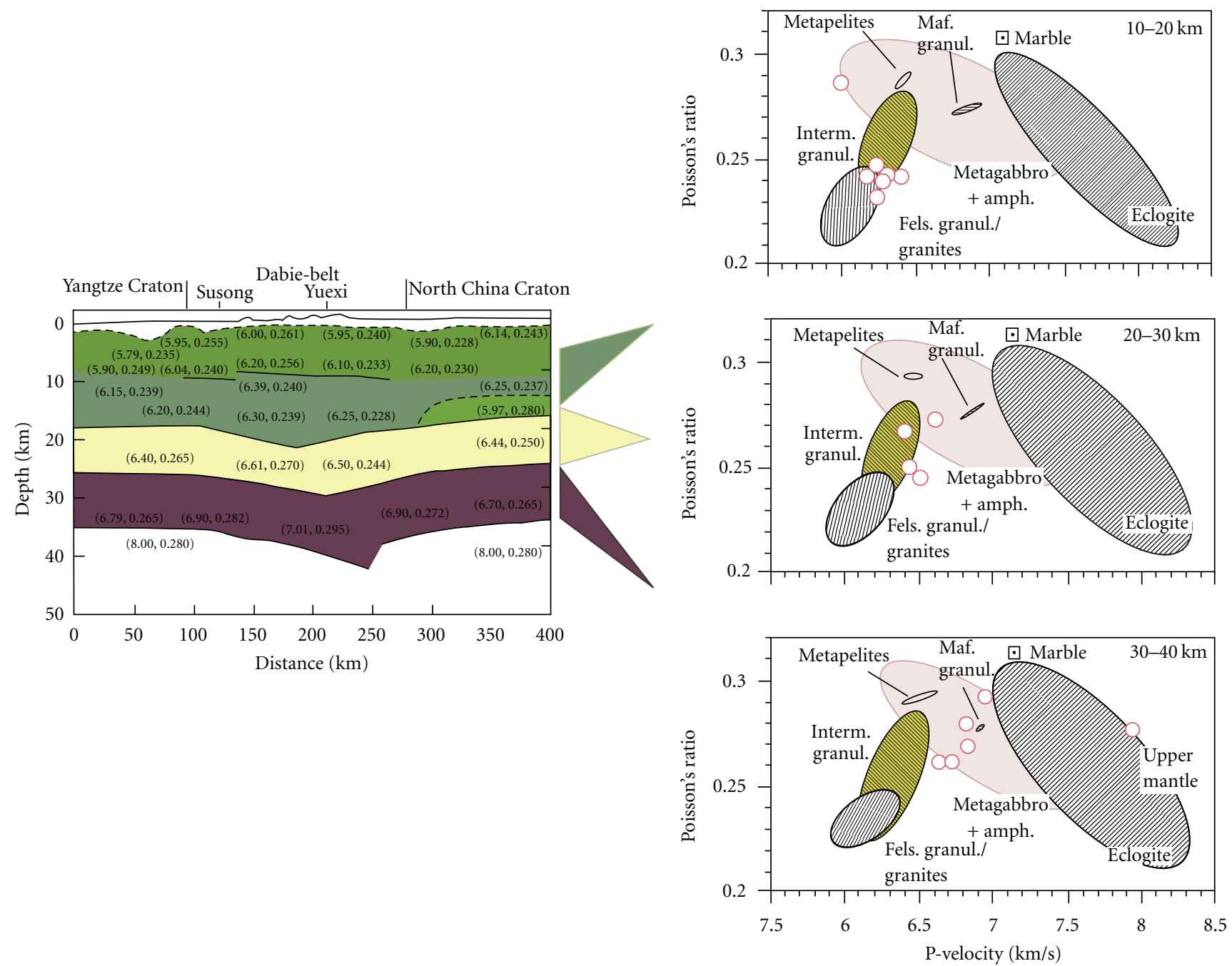

Figure 6: Comparison of ranges of experimentally derived in situ velocities and Poisson's ratios for UHP rocks for various depth of the four-layer crustal structure at Dabie [5] with respective seismic refraction data [26] (red circles). 
combined Vp and Poisson's ratio data, we conclude that eclogite which is exposed in many outcrops is not a volumetrically important constituent of the deep crust in the Dabie mountains. The coupling of the laboratory-derived in situ seismic data (Vp and Poisson's ratio's) with refraction seismic data, along with evidence from geological and geochemical investigations [26], suggests that lower crustal delamination of high-density eclogitic rocks played an important role in the modification of the East China crust [5].

\section{Summary}

Coupling laboratory seismic measurements on crustal rocks from Outokumpu (SE, Finland) and the Dabie mountains (Central China) along with model calculations provided the basis for the following conclusions.

(1) Measured and calculated velocities of relevant rocks sampled by the Outokumpu scientific drill hole (SE Finland) show that variations of lithology within the ophiolite-related assemblage have the potential to generate the strong seismic reflections revealed by the nearby high-resolution seismic reflection line (OKU1) at the depth of $1300 \mathrm{~m}-1500 \mathrm{~m}$. Marked CPO- and crack-related seismic anisotropy of the biotite gneiss series hosting the ophiolite sequence may enhance the seismic reflections at their contacts.

(2) Correlation of in situ velocities and Poisson's ratios derived from $\mathrm{P}$ - and $\mathrm{S}$-wave velocities measured on UHP metamorphic rocks collected from surface exposures in the Dabie mountains (Central China) with respective data of a refraction profile crossing the Dabie metamorphic belt allowed a lithologic interpretation of the velocity structure for the $34 \mathrm{~km}$ thick continental crust. Importantly, the comparison gives clear evidence that eclogite which is exposed in many outcrops is not a main constituent of the lowermost crust in the Dabie mountains.

\section{Acknowledgment}

The help in preparing the figures by Philip Kegler and Detlef Schulte-Kortnack is greatly appreciated.

\section{References}

[1] D. M. Fountain and M. H. Salisbury, "Exposed cross-sections through the continental crust: implications for crustal structure, petrology, and evolution," Earth and Planetary Science Letters, vol. 56, pp. 263-277, 1981.

[2] H. Kern and V. Schenk, "A model of velocity structure beneath Calabria, southern Italy, based on laboratory data," Earth and Planetary Science Letters, vol. 87, no. 3, pp. 325-337, 1988.

[3] H. Downes, C. Dupuy, and A. F. Leyreloup, "Crustal evolution of the Hercynian belt of Western Europe: evidence from lowercrustal granulitic xenoliths," Chemical Geology, vol. 83, no. 3-4, pp. 209-231, 1990.

[4] N. I. Christensen and W. W. Wepfer, "Laboratory techniques for determining seismic velocities and attenuations, with applications to the continental lithosphere," in Geophysical
Framework of the Continental United States, L. C. Pakiser and W. D. Mooney, Eds., vol. 172, Geophysical Society of America Memoir, Boulder, Colo, USA, 1989.

[5] H. Kern, S. Gao, Z. Jin, T. Popp, and S. Jin, "Petrophysical studies on rocks from the Dabie ultrahigh-pressure (UHP) metamorphic belt, Central China: implications for the composition and delamination of the lower crust," Tectonophysics, vol. 301, no. 3-4, pp. 191-215, 1999.

[6] I. Jackson, R. L. Rudnick, S. Y. O'Reilly, and C. Bezant, "Measured and calculated elastic wave velocities for xenoliths from the lower crust and upper mantle," Tectonophysics, vol. 173, no. 1-4, pp. 207-210, 1990.

[7] H. Kern, K. Mengel, K. W. Strauss, T. I. Ivankina, A. N. Nikitin, and I. T. Kukkonen, "Elastic wave velocities, chemistry and modal mineralogy of crustal rocks sampled by the Outokumpu scientific drill hole: evidence from lab measurements and modeling," Physics of the Earth and Planetary Interiors, vol. 175, no. 3-4, pp. 151-166, 2009.

[8] H. Kern, B. Liu, and T. Popp, "Relationship between anisotropy of $\mathrm{P}$ and $\mathrm{S}$ wave velocities and anisotropy of attenuation in serpentinite and amphibolite," Journal of Geophysical Research B: Solid Earth, vol. 102, no. 2, pp. 3051-3065, 1997.

[9] K. Mengel and H. Kern, "Evolution of the petrological and seismic Moho-implications for the continental crust-mantle boundary," Terra Nova, vol. 4, no. 1, pp. 109-116, 1992.

[10] F. Birch, "The velocity of compressional wave velocities in rocks to 10 kbar, part 2," Journal of Geophysical Research, vol. 66, pp. 2199-2224, 1961.

[11] L. Burlini and D. M. Fountain, "Seismic anisotropy of metapelites from the Ivrea-Verbano zone and Serie dei Laghi (Northern Italy)," Physics of the Earth and Planetary Interiors, vol. 78, no. 3-4, pp. 301-317, 1993.

[12] G. Barruol and H. Kern, "Seismic anisotropy and shear-wave splitting in lower-crustal and upper-mantle rocks from the Ivrea Zone-experimental and calculated data," Physics of the Earth and Planetary Interiors, vol. 95, no. 3-4, pp. 175-194, 1996.

[13] H. Kern, T. Popp, F. Gorbatsevich, A. Zharikov, K. V. Lobanov, and Y. U. P. Smirnov, "Pressure and temperature dependence of $\mathrm{Vp}$ and $\mathrm{Vs}$ in rocks from the superdeep well and from surface analogues at Kola and the nature of velocity anisotrophy," Tectonophysics, vol. 338, no. 2, pp. 113-134, 2001.

[14] H. Kern and H. R. Wenk, "Fabric-related velocity anisotropy and shear wave splitting in rocks from the Santa Rosa mylonite zone, California," Journal of Geophysical Research, vol. 95, no. 7, pp. 11213-11223, 1990.

[15] S. Ji and M. H. Salisbury, "Shear-wave velocities, anisotropy and splitting in high-grade mylonites," Tectonophysics, vol. 221, no. 3-4, pp. 453-473, 1993.

[16] S. Crampin, "Geological and industrial implications of extensive-dilatancy anisotropy," Nature, vol. 328, no. 6130, pp. 491-496, 1987.

[17] T. I. Ivankina, H. Kern, and A. N. Nikitin, "Neutron texture measurements and $3 \mathrm{D}$ velocity calculations on strongly foliated biotite gneissses from the Outokumpu Deep Drill Hole," in Proceedings of the 2nd International Workshop Outokumpu Deep Drilling Project, I. T. Kukkonen, Ed., Program and Extended Abstracts. Geological Survey of Finland, Espoo, Finland, 2007.

[18] H. Kern, T. I. Ivankina, A. N. Nikitin, T. Lokajicek, and Z. Pros, "The effect of oriented microcracks and crystallographic and shape preferred orientation on bulk elastic anisotropy of a foliated biotite gneiss from Outokumpu," Tectonophysics, vol. 457, no. 3-4, pp. 143-149, 2008. 
[19] E. M. Chesnokov, D. K. Tiwary, I. O. Bayuk, M. A. Sparkman, and R. L. Brown, "Mathematical modelling of anisotropy of illite-rich shale," Geophysical Journal International, vol. 178, no. 3, pp. 1625-1648, 2009.

[20] P. J. Heikkinen, E. Koivisto, and I. T. Kukkonen, "FIRE high resolution seismic survey in Outokumpu," in Proceedings of the 2nd International Workshop Outokumpu Deep Drilling Project, I. T. Kukkonen, Ed., pp. 47-50, Program and Extended Abstracts. Geological Survey of Finland, Espoo, Finland, 2007.

[21] I.T. Kukkonen, P. Heikkinen, E. Ekdahl et al., "Acquisition and geophysical characteristics of reflection seismic data on FIRE transects, Fennoscandian Shield," in Finnish Reflection Experiment 2001-2005, I. T. Kukkonen and R. Lahtinen, Eds., pp. 241-246, Geological Survey of Finland, Espoo, Finland, 2006.

[22] H. Gebrande, "Elastic wave velocities and constants of elasticity of rock-forming minerals," in Physical Properties of Rocks, G. Angenheister, Ed., vol. 1, pp. 1-96, Springer, New York, NY, USA, 1982.

[23] M. Warner, "Absolute reflection coefficients from deep seismic reflections," Tectonophysics, vol. 173, no. 1-4, pp. 15-23, 1990.

[24] J. G. Liou, Q. Wang, M. Zhai, R. Y. Zhang, and B. Cong, "Ultrahigh-P metamorphic rocks and their associated lithologies from the Dabie Mountains, Central China," in Proceedings of the 3rd International Eclogite Field Symposium, vol. 40, Chinese Science Bulletin, 1995.

[25] C. Y. Wang, Z. F. Ding, J. L. Song, Q. J. Wu, J. I. C. Zheng, and X. B. Zhang, "Shear wave velocity structure in Dabieshan orogenic belt," Acta Geophysica Sinica, vol. 40, no. 3, pp. 344-346, 1997.

[26] S. Gao, B. R. Zhang, Z. M. Jin, H. Kern, T. C. Luo, and Z. I. D. Zhao, "How mafic is the lower continental crust?" Earth and Planetary Science Letters, vol. 161, no. 1-4, pp. 101-117, 1998. 

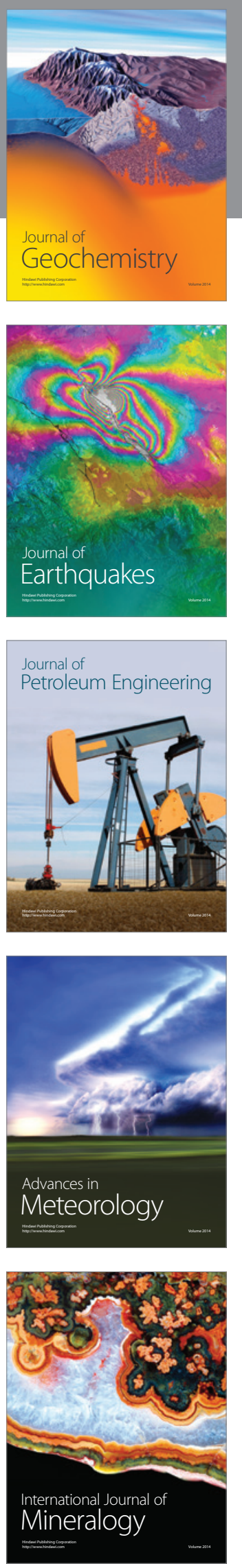
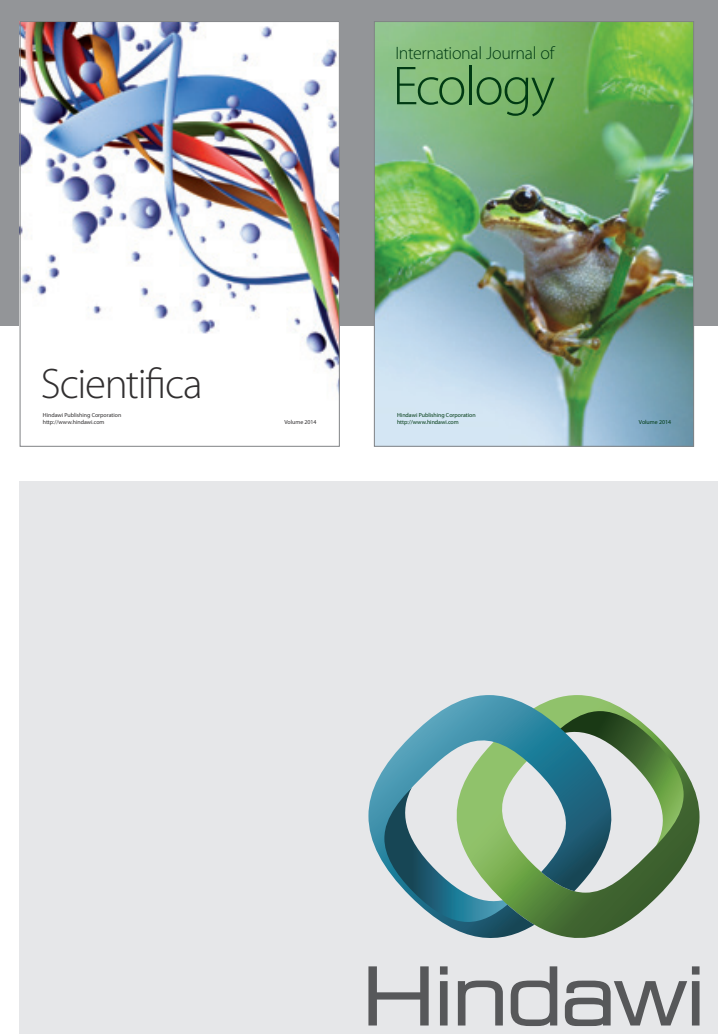

Submit your manuscripts at http://www.hindawi.com
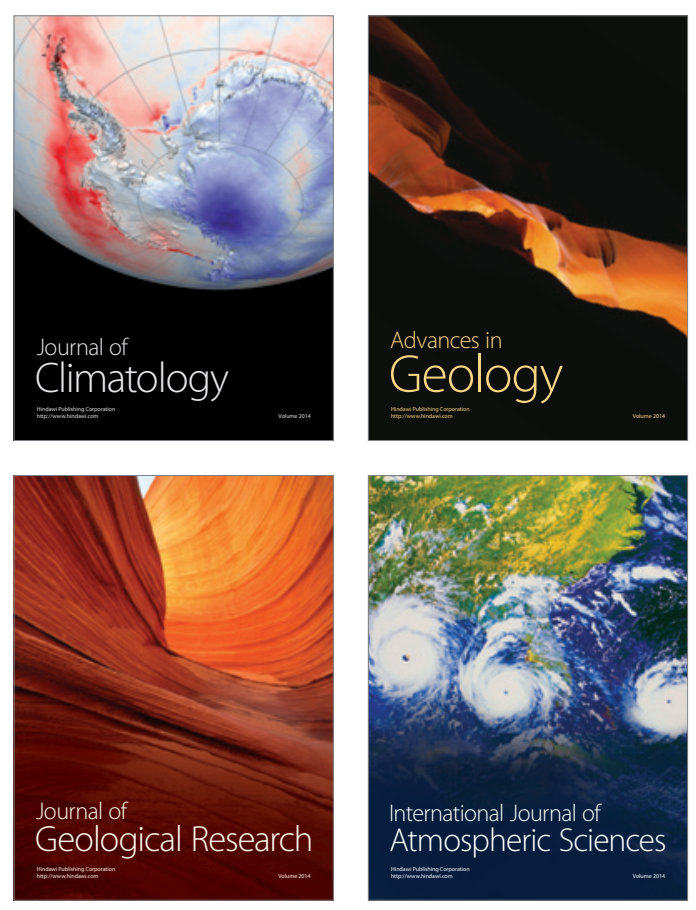
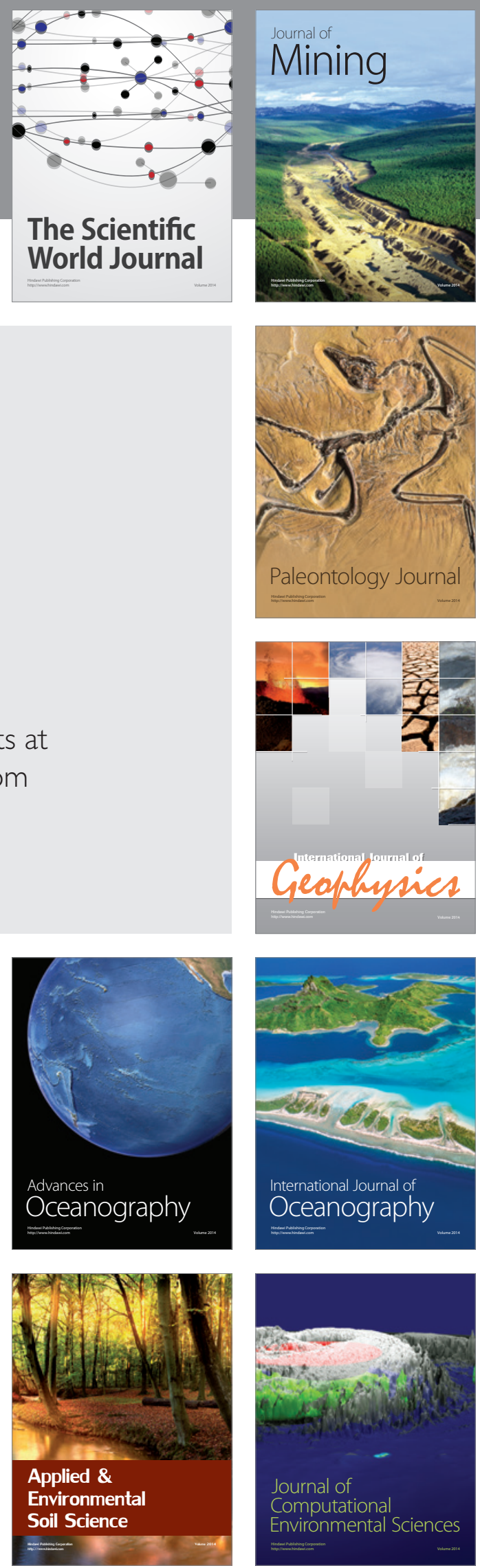